Max-Planck-Institut für demografische Forschung

Max Planck Institute for Demographic Research

Konrad-Zuse-Strasse 1 - D-18057 Rostock · GERMANY

Tel +49 (0) 3812081 - 0; Fax +49 (0) 3812081 - 202;

http://www.demogr.mpg.de

MPIDR WORKING PAPER WP 2007-019

MAY 2007

\title{
Demography, present and future
}

Jan M. Hoem (hoem@demogr.mpg.de)

This working paper has been approved for release by: Jan M. Hoem (hoem@ demogr.mpg.de)

Head of the Laboratory of Contemporary European Fertility and Family Dynamics.

(C) Copyright is held by the authors.

Working papers of the Max Planck Institute for Demographic Research receive only limited review. Views or opinions expressed in working papers are attributable to the authors and do not necessarily reflect those of the Institute. 
JMH/-, 4 August 2006.

Revised 21 August 2006.

\title{
Demography, present and future.
}

\section{By invitation, reflections in response to Dominique Tabutin's essay on strengths and weaknesses of the demographic discipline over fifty years}

\author{
by Jan M. Hoem ${ }^{1}$
}

There is an interesting tension between optimism and pessimism in the considerations in the original essay. ${ }^{2}$ I find myself largely in agreement with the author's sentiments, but on a number of items I have a more muted attitude or a different diagnosis. In what follows I concentrate on three main issues that have struck me as I read the text.

1. Understanding and explanation: I agree strongly with the need to keep the discipline moving toward understanding and explaining demographic phenomena, but my reading of the trends is more optimistic than Tabutin's. I believe that the discipline has been on the move in the right direction for a good while already. Remember that already the Princeton Project challenged economistic approaches. Over time demographers have incorporated theoretical and methodological approaches from fields like anthropology, sociology, psychology, cultural studies, and gender studies. Colleagues in these fields may look for a stronger integration of their own contributions, but in any case they have had much impact on demographic thinking, and also on demographic survey construction, data collection, and data analysis. In turn this has led to more complex and sophisticated insights into what drives demographic development and demographic behavior. The latest development may be the incorporation of institutional approaches, resulting in increased attention to contextual issues, social networks, public policy, and political and environmental developments. This has further broadened the theoretical and methodological basis of the discipline and has brought demography closer to one of the goals that Tabutin has formulated, namely a genuinely social demography. I welcome the recent diversification, and in particular I welcome that demographers have moved toward breaking the monopoly on theoretical formulation that many economists and other advocates of a purely utility-oriented rationalchoice approach have too long felt entitled to.

I am less enthusiastic about one recent countermovement, perhaps still in its infancy, where demographers have started to resort to biology or genetics to find explanations for current demographic developments. I do not question contributions that these two disciplines can make to demography (for instance in developing new reproductive techniques or in understanding long-term mortality trends), but I do not see how genetic or biological explanations can give us deeper insights into, say, recent fertility developments in Europe. Are we to take changes in the gene pool or in medical reproductive capacity as an explanation of the recent drop in fertility? I would rather like us to pursue the "imperative requirement" (to adopt a term from Tabutin) that our discipline should maintain and expand its socialscience aspects.

In addition I would like to give a different emphasis than Tabutin to a couple of items:

(i) Description: I do not see a necessary conflict between description and explanation. Just as in many other disciplines, careful description is an important and integral part of

\footnotetext{
${ }^{1}$ Max Planck Institute of Demographic Research, Rostock. I deeply appreciate input from Gerda Neyer and Hill Kulu.

2 Tabutin, Dominique: What sort of demography in the future? Strengths, weaknesses and changes over fifty years of the discipline. Presentation to the IUSSP Conference in Tours 2005; to appear in Population in 2006.
} 
substantive explanation in demography, and demographers are supposed to be good at it. We should not let this feature get lost when we support other developments.

(ii) Methods: In the search for explanation, the ability to use suitable statistical tools is important; in fact mastery of such tools is a prerequisite for the formulation of many scientific questions and for assessing the validity of scientific explanations. I agree that the methodology should not be an end in itself - what discipline would continue to develop if that were the case? But among demographers I rather see a danger in the opposite direction, namely in a widespread reluctance against adopting modern methods. It does not pay to develop demographic procedures in isolation from professional statistical principles any more than it pays in other disciplines. The probabilistic approach is the way to a deeper understanding of inferential techniques and to further methodological development beyond intuitive reasoning. I see no reason why demography should deprive itself of this opportunity. The trick is to combine innovation in substantive theory and understanding with appropriate statistical methods.

(iii) In continuation of item (ii) I contend that one needs to break the grip that classical, non-probabilistic procedures based on aggregate data now have on demographic analysis. A deeper understanding of demographic behavior requires the study of data for the individual, or for the couple, for extended families, or for social networks. I would root for the incorporation of event-history analysis as a standard ingredient in graduate-level education in demography, perhaps at the expense of some of the attention now given to more conventional methods. There is an old-standing concern among demographers that the analyst may be locked into continuously committing an atomistic fallacy - namely treating behavior as if there were no interaction between individuals, and letting the fact that individuals live in societies get lost from sight. Both conventional macro-based non-probabilistic methods and some usages of individual-level (probabilistic) survival analysis entail this risk. I suspect that some of that new reliance on genetic and biological items might do so too. Right now the best tool to overcome such difficulties is multi-state multi-level event-history analysis based on individual-level data combined with society-level data on the social environment. More attention should be given to its possibilities than to any fear that demographers could be overwhelmed by their own statistical prowess.

2. The size of the discipline: I agree with Tabutin that the small number of academic demographers is a perennial and threatening problem for demography as a discipline. The European international doctoral schools have been devised to address this issue. Of course they cannot solve "all" teaching problems, but these schools are one of the really encouraging features of the current scene. Their programs have lead to great improvement in both quality and quantity of recruitment to the discipline; in fact they have contributed significantly to shaping a new European demographic identity in the younger generations. It would augur well for the aftergrowth in demography if these schools could continue to operate and develop. I strongly wish that they could expand further to include more courses that cover theories, approaches, and methodologies of a variety of other disciplines in order to broaden the explanatory strength of demography that Tabutin calls for. I also strongly hope that more countries in Europe would learn to participate in this venture and make use of the opportunities that such transnational education and collaboration offers.

Another cause for optimism is the quickly increasing attention that demographic issues have received lately from politicians, the media, and the general public. It is a challenge for current senior demographers to take advantage of this new-found interest and convert it to improvements for the discipline, including a strengthening of the position demography has in European universities. Surely some inspiration can be found in the program-building activities of our American counterparts in the heyday of interest in developing countries and family planning. 
3. Tabutin's five imperative requirements: Despite whatever differences one can see above in approach and emphasis, I find myself mostly in agreement with the diagnosis and recommendations in his five-point summary. Just like her, I am in favor of more social demography and of a strong stress on explanation. Like his I also feel that qualitative aspects of demography should be strengthened, and that the discipline would benefit from a stronger engagement in social-political issues. In particular I feel that we should maintain a high profile in such issues in Europe. The diversity of Europe and the current demographic and social-political developments in European countries offer unique opportunities to further the discipline since it forces us to overcome any national parochialism in research and to move towards comparative, transnational research and explanations.

I finally agree that we should welcome improvement in the way demography is taught. In particular we should seek a better integration of theory and explanation with techniques of analysis in our teaching. I doubt that extensive initiatives in this direction can be expected from the universities; with few exceptions European university demographers are located in tiny units, often subject to the toleration of larger disciplines. At the current time of economic adversity, educational innovation seems to be mostly in the hands of the larger demographic institutes and their educational programs. We must hope that more universities see it in their interest to cooperate with these programs and to facilitate participation for their students. 